\title{
Photometric and Colorimetric Properties of the Solar Aureole
}

\author{
By Kimio Arao \\ Faculty of Education, Nagasaki University, Nagasaki 852, Japan \\ and \\ Masayuki Tanaka \\ Upper Atmosphere and Space Research Laboratory, Tohoku University, Sendai 980, Japan \\ (Manuscript received 6 July 1987, in revised form 14 December 1987)
}

\begin{abstract}
Based on accurate solutions of the transfer of solar radiation for realistic models of the turbid atmosphere, the photometric and colorimetric properties of the solar aureole were studied for various conditions of atmospheric turbidity. The radiation flux density in the vicinity of the sun becomes more predominant for turbid conditions especially at shorter visible wavelengths. In spite of this general feature, the percentage error of the Angström's turbidity parameter due to the aureole flux density involved in the sunphotometry becomes more serious for clear conditions than for turbid conditions. This is because even a small aureole flux density added to the direct solar radiation diminishes the aerosol optical thickness significantly for clear conditions. The colorimetric property of the solar aureole varies noticeably place by place for the atmosphere containing larger particles, although the most reddish (the lowest color temperature) point does not change its position of about $1.6^{\circ}$ from the sun for different turbidity conditions. Comparing with non-absorbing aerosols, absorbing aerosols make the aureole region more bluish for clear conditions, and more reddish for turbid conditions.
\end{abstract}

\section{Introduction}

Many observational and theoretical studies on the solar aureole have been carried out with special interest in the retrieval of the size distribution of aerosols and their optical properties. The photometric and photographic measurements of the solar aureole have been developed extensively (e.g. Shaw and Deehr, 1975; McPeters and Green 1976; Deepak and Adams, 1983). The traditional idea of utilizing the solar aureole as a measure of the atmospheric turbidity has been adopted repeatedly (e.g. Ångström, 1974; Nakajima et al., 1983; Tanaka et al., 1986). The effect of the solar aureole on the Angström pyrheliometric scale, or on the determination of the optical thickness of aerosols, has been discussed (e.g. Major, 1973;

(C) 1988, Meteorological Society of Japan
Box and Deepak, 1979). However, most of these studies adopted some approximations, such as Deirmendjian's first-order perturbation technique (Deirmendjian, 1957, 1959), and avoided treating accurately the multiply scattered radiation due to aerosols.

Recently, we presented a new method of evaluating the aureole intensity with higher accuracy taking fully into account the multiple scattering due to aerosols and air molecules, and showed the angular and spectral distributions of the aureole intensity for several realistic models of the turbid atmosphere, thus obtained (Arao and Tanaka, 1986). In this paper, we extend our discussion to 1) the effect of the circumsolar radiation on the measurement of direct solar radiation, 2) the error in the determination of atmospheric turbidity due to additional circum- 
solar radiation, and 3) the colorimetric property of the solar aureole.

\section{Atmospheric models}

The atmospheric models and the values of involved parameters are the same as in our first paper (Arao and Tanaka, 1986), and only a brief description is given here. The size distribution of aerosols is assumed to obey a power-law distribution of the form,

$n(r)= \begin{cases}C \cdot(0.1)^{-\gamma}, & \text { for } 0.023 \mu \mathrm{m} \leqq r \leqq 0.1 \mu \mathrm{m} \\ C r^{-\gamma}, & \text { for } 0.1 \mu \mathrm{m}<r \leqq 10 \mu \mathrm{m}\end{cases}$

where $n(r) d r$ is the number of aerosols in the vertical air column with radii between $r$ and $r+d r$ and $C$ is a constant. Three values of 3.5, 4.0 and 4.5 are assumed for the exponent $\gamma$. The complex index of refraction of aerosols is assumed to be $m=1.50-0.0 \mathrm{i}$ and $1.50-0.01 \mathrm{i}$. We denote the optical thickness of aerosols at 0.5 $\mu \mathrm{m}$ wavelength by $T_{m}$, and use this as the index of atmospheric turbidity.

The spectral intensity of the extraterrestrial solar radiation is adopted from Thekaekara (1974) and the optical thickness of the Rayleigh atmosphere from Elterman (1968). The ground surface is assumed to be Lambertian with the reflectivity of $A=0.15$ for all wavelengths. Computations are carried out for wavelengths of $\lambda=0.35,0.45,0.55,0.65,0.725,0.825,0.925$, $1.13,1.385,1.89$ and $2.55 \mu \mathrm{m}$.

\section{Flux density of the solar aureole}

The flux density of diffuse radiation involved in the aureole region increases significantly with the increase of the atmospheric turbidity, i.e. the aerosols amount; the ratio of the circumsolar radiation to the direct solar radiation increases with atmospheric turbidity. The spectral flux density of the circumsolar radiation within a circle of an angle $\Theta *$ from the sun can be given by

$$
F_{\lambda}\left(\Theta^{*}\right)=2 \pi \int_{0}^{\Theta^{*}} I_{\lambda}\left(\theta^{*}\right) \sin \theta^{*} d \theta^{*},
$$

where $I_{\lambda}\left(\theta^{*}\right)$, is the intensity of the diffuse radiation as a function of the angle $\theta^{*}\left(=\cos ^{-1}\right.$ $\left(\cos \theta_{0} \cos \theta+\sin \theta_{0} \sin \theta \cos \varphi\right) ; \theta_{0}$ and $\theta$ being the zenith angles of the sun and sky radiation, and $\varphi$ the azimuth angle between the sun and the radiation). As is well known, the intensity of the circumsolar radiation depends more or less on the zenith angle around the sun even for the same values of the angle $\theta^{*}$ because of the multiple scattering. We assumed that the intensity in the solar almucantar (i.e. a circle with the same zenith angle as that of the sun) can represent the average intensity of circumsolar radiation.

The sun was assumed to be a point source, and the diffuse radiation within the solar disk (i.e. $\quad \theta^{*}<0.267^{\circ}$ ) was treated as a part of the sky radiation, though its contribution to the aureole flux density is insignificant because of very small values of $\sin \theta^{*}$. Since the International Radiation Commission (1965) recommended that the viewing angle of the pyrheliometer should be $4.0^{\circ}$ or less, we discuss here the flux density of the circumsolar radiation within the region of $\Theta^{*} \leqq 4.0^{\circ}$.

Figure 1 shows the ratio of the aureole flux density within $\Theta^{*}=4.0^{\circ}$ to the flux density of the direct solar radiation for $\lambda=0.45 \mu \mathrm{m}, \gamma=$

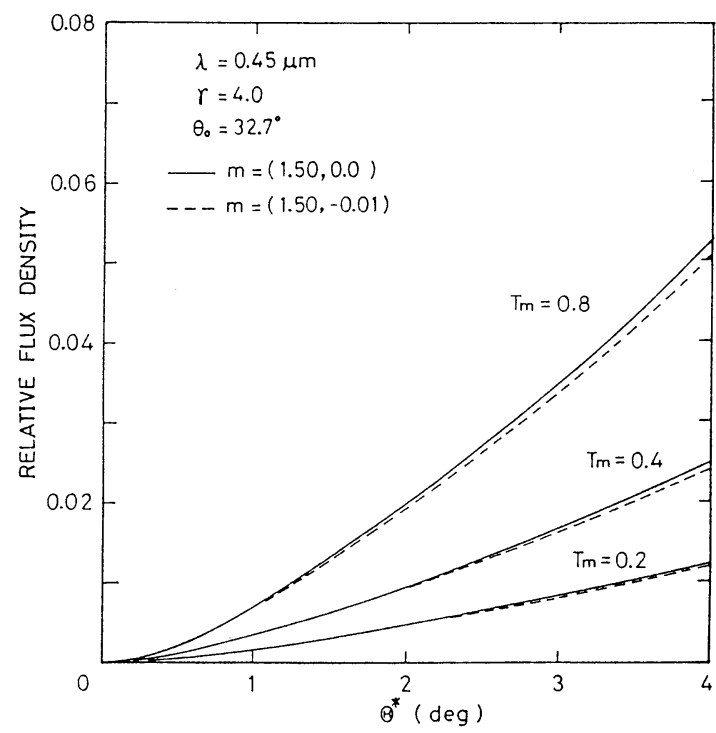

Fig. 1. Spectral aureole flux density within a region of $\theta^{*} \leqq \Theta^{*}$ normalized by the flux density of direct-solar radiation for $\lambda=0.45 \mu \mathrm{m}, \gamma=4.0, \theta_{0}$ $=32.7^{\circ}$, taking $T_{m}$ and $m$ as parameters. 
4.0 and $\theta_{0}=32.7^{\circ}$, taking the optical thickness of aerosols at $\lambda=0.5 \mu \mathrm{m}, T_{m}$, and refractive index of aerosols, $m$, as parameters. Similar results for $\gamma=3.5$ and 4.5 are shown in Fig 2 . These figures show that the ratio of the flux density of the solar aureole to that of direct solar radiation for $\lambda=0.45 \mu \mathrm{m}$ and $T_{m}=0.8$ amounts to about 3,5 and $10 \%$ for $\gamma=4.5,4.0$ and 3.5 , respectively. The value of this ratio is roughly proportional to the value of $T_{m}$, i.e. $1 / 2$ and $1 / 4$ for $T_{m}=0.4$ and 0.2 , respectively. Figure 3 shows the same quantity as a function of wavelength for $\gamma=4.0, \theta_{0}=59.2^{\circ}$ and $T_{m}=$ $0.8,0.4$ and 0.2 . It is apparent from this figure that the flux density of the direct solar radiation is significantly influenced by the aureole flux density, especially for higher turbidity and at shorter wavelengths. As can be seen from Figs. 1 and 2 , this influence is most significant for the case of $\gamma=3.5$.

With respect to these figures, Box and Deepak (1979) have shown that under most relatively clear sky conditions, the diffuse contribution to the total measured irradiance will be less than, or

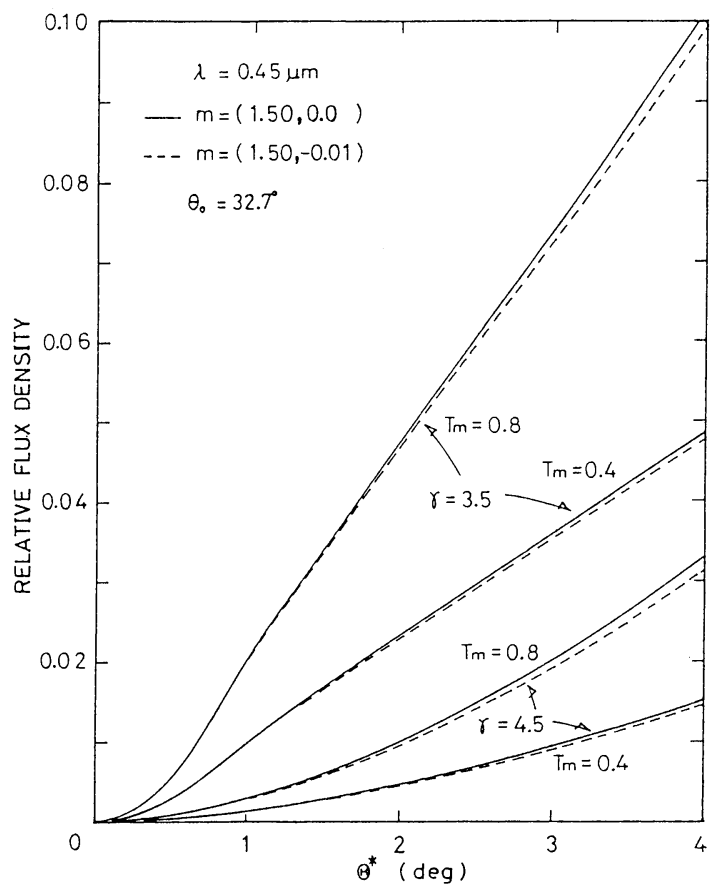

Fig. 2. Same as Fig. 1 but for $\gamma=3.5$ and 4.5 . the order of, $1 \%$. Since they restricted their discussion to the case of low turbidity such as aerosol optical depths of 0.1 to 0.2 , their conclusion corresponds to the cases of $T_{m} \leqq 0.2$ in the present study. Therefore, the results in lower turbidity conditions shown in Figs. 1-3 obviously agree with those of Box and Deepak.

The flux density of the circumsolar radiation integrated over wavelength was also evaluated taking account of the absorption of both water vapor and ozone. The spectral region treated in this study was from $\lambda=0.30$ to $3.0 \mu \mathrm{m}$, and the total flux density of the direct solar radiation at the top of the atmosphere was assumed to be $1.307 \mathrm{KW} / \mathrm{m}^{2}$, which is equal to $96.6 \%$ of the solar constant given by Thekaekara (1974). The absorption of ozone in the Chappius bands (0.44-0.75 $\mu \mathrm{m})$ was taken into account by reducing the incident solar radiation in advance; ozone was assumed to absorb the solar radiation before the scattering due to air molecules and aerosols took place. The amount of ozone was assumed to be 300 Dobson units. The absorption coefficients of ozone were obtained from Vigroux (1953). As for the absorption of water vapor, single scattering approximation was adopted for the respective seven absorption bands at $0.7,0.8,0.9,1.1,1.4,1.8$ and $2.7 \mu \mathrm{m}$,

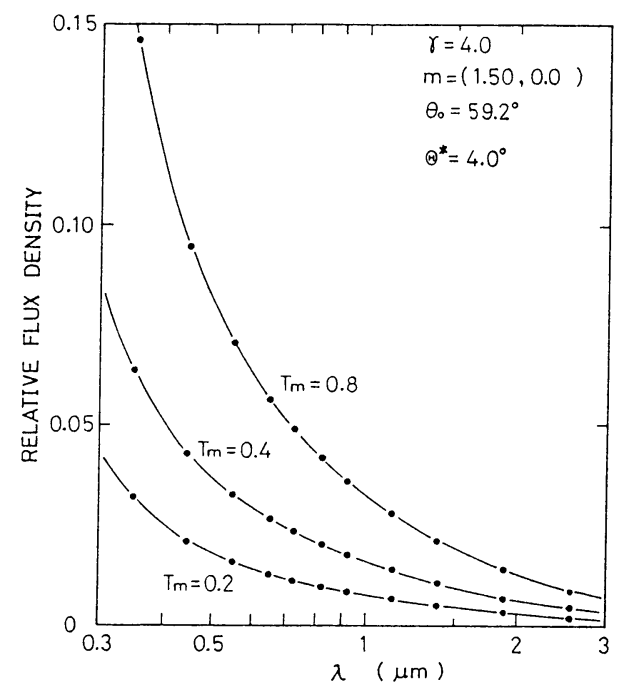

Fig. 3. Spectral aureole flux density of $\Theta^{*}=4.0^{\circ}$ normalized by the flux density of direct-solar radiation versus wavelength $\lambda$ for $\gamma=4.0, m=$ $(1.50,0.0)$ and $\theta_{0}=59.2^{\circ}$. 
because of decreased values of the single scattering albedo. The exponential-sum fitting of the transmission functions of the respective water vapor bands were adopted from Raschke and Stucke (1973). The water vapor contents in the vertical air column (or precipitable water), $w$, were assumed to be $0.5,1.5$ and 4.5 grams.

The integrated flux densities of both directsolar and circumsolar radiations are shown in Fig. 4 for $\gamma=4.0, \theta_{0}=32.7^{\circ}, m=(1.50,0.0)$ and $T_{m}=0.2,0.4$ and 0.8 . Although both of the direct-solar and circumsolar flux densities decrease in a similar manner with an increase of the precipitable water, it is noticeable that the decrease of the direct-solar flux density is a little more conspicuous if compared carefully. This is because the aureole flux density is more predominant in the shorter wavelength region where no absorption of water vapor occurs. Accordingly, the ratio of the aureole flux density to the direct-solar flux density increases with an increase of the precipitable water.

Figure 5 shows the ratio of the flux density of diffuse radiation to that of the direct radiation as

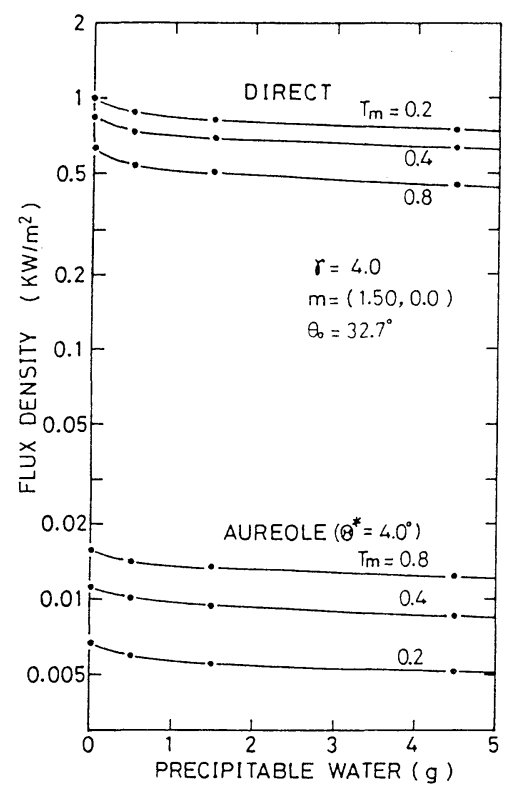

Fig. 4. Total direct-solar radiations and the corresponding flux densities of the aureole versus precipitable water $w$ for $\gamma=4.0, m=(1.50,0.0)$ and $\theta_{0}=32.7^{\circ}$, taking $T_{m}$ as a parameter. a function of $\Theta *$ for $\gamma=4.0, \theta_{0}=59.2^{\circ}$ and $m$ $=1.50-0.0 \mathrm{i}$ and 1.50-0.01i, taking $T_{m}$ and $w$ as parameters. The change of this ratio for the change of $w$ from 0 to $4.5 \mathrm{~g}$ is about two-fold of that of the change of the imaginary index of refraction $m$ from 0.0 to 0.01 ; the absorption of water vapor for $w=0.5 \mathrm{~g}$ is comparable with that of absorbing aerosols with the imaginary index of 0.01 . The aureole flux density at $\Theta^{*}=4.0^{\circ}$ is about $2 \%$ of the direct flux density for $T_{m}=0.4$ and about $4 \%$ for $T_{m}=0.8$, for the case of $\gamma=$ 4.0. Although not shown in the figure, the corresponding values for $\gamma=3.5$ and 4.5 are 4.5 and $0.9 \%$, for $T_{m}=0.4$, respectively.

Figure 6 shows the flux density of the circumsolar radiation in each doughnut-shaped ring of $1^{\circ}$ width for $\theta_{0}=47.6^{\circ}, T_{m}=0.4, w=$ $1.5 \mathrm{~g}$ and $m=(1.50,0.0)$ and $(1.50,-0.01)$, taking $\gamma$ as a parameter. The flux densities for $\gamma=4.0$ and 4.5 increase monotonically with an increase of $\theta^{*}$, mainly due to an increase of the solid angle. On the other hand, the case for $\gamma=3.5$ shows two maximums around $\theta^{*}=2$ and $6^{\circ}$, reflecting the shape of the strong forward scattering lobe due to large particles. Another interesting feature in Fig. 6 is that the flux densities in the inner rings are rather insensitive

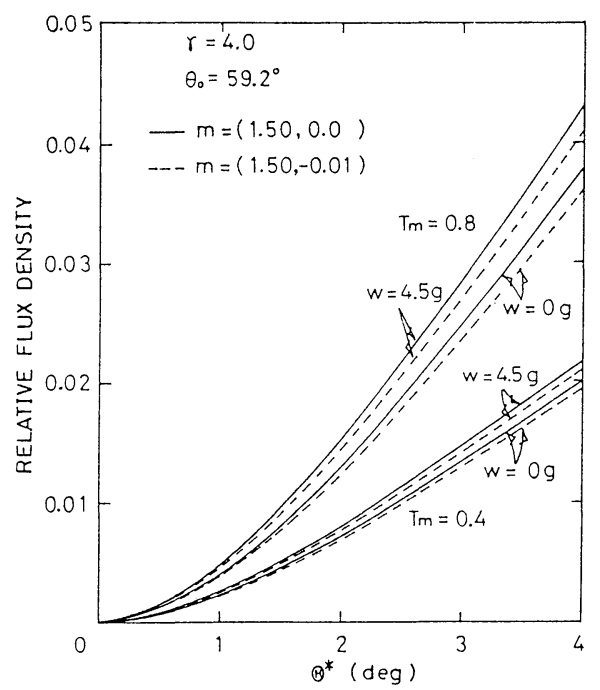

Fig. 5. Total flux density of the aureole normalized by that of the direct-solar radiation versus $\Theta *$ for $\gamma=$ 4.0 and $\theta_{0}=59.2^{\circ}$, taking $m, T_{m}$ and $w$ as parameters. 


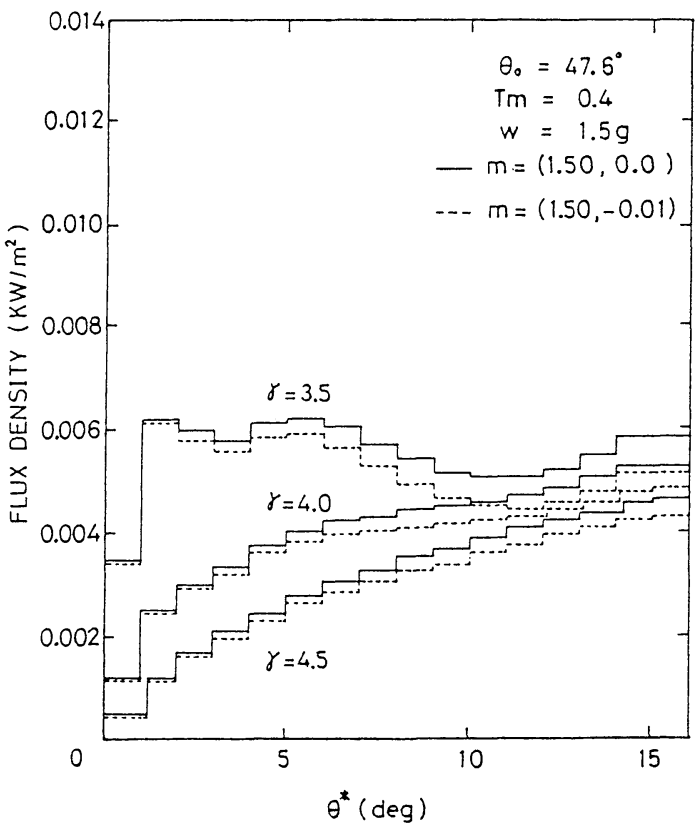

Fig. 6. Flux density of circumsolar radiation emerging from each $1^{\circ}$-interval ring versus $\theta^{*}$ for $\theta_{0}=47.6^{\circ}$, $T_{m}=0.4$ and $w=1.5 \mathrm{~g}$, taking $\gamma$ and $m$ as parameters.

to the imaginary part of the index of refraction, while those of the outer rings are very sensitive, especially for $\gamma=3.5$. Thus, the circumsolar radiation measured for different rings is expected to provide some detailed knowledge of the physical properties of aerosols.

\section{Effect of the aureole on determination of turbidity parameters}

As shown in the previous section, the flux density of aureole cannot be disregarded, especially at shorter visible wavelengths and in turbid conditions. We therefore examined the effect of the aureole flux density on the determination of the optical thickness of aerosols or the turbidity parameters. The Angström's turbidity parameters $\alpha$ and $\beta$ are defined by the expression

$$
\tau_{M}(\lambda)=\beta \lambda^{-\alpha},
$$

where $\tau_{M}$ is the optical thickness of aerosols, $\alpha$ is the wavelength exponent and $\beta$ is the turbidity coefficient (Ångström, 1964). The estimated values of the optical thickness of aerosols, and accordingly the Angström's turbidity parameters $\alpha$ and $\beta$, depend on the accuracy of the direct solar radiation measurements. Table 1 shows the values of $\alpha$ and $\beta$ corresponding to three different measurements of the direct solar radiation, for $\theta_{0}=47.6^{\circ}, m=$ $(1.50,0.0)$ and $\gamma=3.5$ and 4.0. In the table, $\alpha_{0}$ and $\beta_{0}$ indicate the true values of the parameters, which can be evaluated from an ideal measurements of the direct solar radiation eliminating the solar aureole. The combinations of $\left(\alpha_{2}, \beta_{2}\right)$ and $\left(\alpha_{4}, \beta_{4}\right)$ indicate the parameter values estimated from apparent direct-solar radiation including the aureole flux densities within the region of $\theta^{*} \leqq 2.0^{\circ}$ and $\theta^{*}$ $\leqq 4.0^{\circ}$, respectively. Two different values of the parameters shown in the table correspond to two different pairs of $\lambda=0.35$ and $0.65 \mu \mathrm{m}$ and $\lambda=$ 0.45 and $0.65 \mu \mathrm{m}$, respectively.

The effect of the solar aureole on the Ångström's turbidity parameters is substantial especially for the case of $\gamma=3.5$ and for the wavelength pair of $\lambda=0.35$ and $0.65 \mu \mathrm{m}$. It is noticed that the percentage errors in clear conditions are comparable with or more than those in turbid conditions. This feature can be attributed to the fact that the optical thickness of aerosols obtained from apparent direct-solar radiation which includes the aureole flux density in clear conditions decreases significantly in spite of a very small contribution of the aureole. The values for $\gamma=4.5$ are not shown in the table, because corresponding errors are as small as one percent or less.

From the above results it is concluded that the aureole flux density at shorter visible wavelengths should be treated carefully not only in turbid conditions but also in clear conditions for accurate measurements of the optical thickness of aerosols and turbidity parameters; a photometer with a sufficiently small aperture angle is required for the direct-solar radiation measurements at least at shorter visible wavelengths. The aureole effect for absorbing aerosols with $m=(1.50,-0.01)$ is almost similar to the case of non-absorbing aerosols with $m=(1.50$, 0.0 ), because the single scattering due to the Fraunhofer diffraction lobe dominates in the small scattering angles considered here. 
Table 1. Angström's turbidity parameters and their percentage errors for three kinds of the direct solar radiation measurements and two cases of wavelength pair, for the case of $m=(1.50,0.0)$ and $\theta_{0}=$ 47.6 . Suffixial numbers 0,2 and 4 indicate the scattering angles in degree within which the aureole flux density was taken into account as a fraction of the direct solar radiation. $\lambda_{1}$ and $\lambda_{2}$ are the wavelengths from which the parameters were evaluated. Percentage errors compared with true values, $\alpha_{0}$ and $\beta_{0}$, are shown in parentheses.

\begin{tabular}{|c|c|c|c|c|c|c|c|c|}
\hline$\gamma$ & $\lambda_{1} \& \lambda_{2}(\mu \mathrm{m})$ & $T_{m}$ & $\alpha_{0}$ & $\beta_{0}$ & $\alpha_{2}$ (error, $\left.\%\right)$ & $\beta_{2}($ error, \%) & $\alpha_{4}($ error, $\%)$ & $\beta_{4}($ error, $\%)$ \\
\hline \multirow[t]{8}{*}{3.5} & $\lambda_{1}=0.35$ & 0.1 & 0.469 & 0.072 & $0.441(6.0)$ & $0.070(2.8)$ & $0.402(14.3)$ & $0.068(5.6)$ \\
\hline & $\lambda_{2}=0.65$ & 0.2 & .469 & .143 & $.445(5.1)$ & $.139(2.8)$ & $.415(11.5)$ & $.135(5.6)$ \\
\hline & & 0.4 & .470 & .286 & $.447(4.9)$ & $.278(2.8)$ & $.422(10.2)$ & $.268(6.3)$ \\
\hline & & 0.8 & .470 & .572 & $.446(5.1)$ & $.556(2.8)$ & $.421(10.4)$ & $.536(6.3)$ \\
\hline & $\lambda_{1}=0.45$ & 0.1 & 0.497 & 0.071 & $0.474(4.6)$ & $0.069(2.8)$ & $0.452(9.1)$ & $0.066(7.0)$ \\
\hline & $\lambda_{2}=0.65$ & 0.2 & .498 & .141 & $.476(4.4)$ & $.137(2.8)$ & $.458(8.0)$ & $.132(6.4)$ \\
\hline & & 0.4 & .498 & .283 & $.476(4.4)$ & $.275(2.8)$ & $.459(7.8)$ & $.264(6.7)$ \\
\hline & & 0.8 & .498 & .565 & $.476(4.4)$ & $.549(2.8)$ & $.458(8.0)$ & $.527(6.7)$ \\
\hline \multirow[t]{8}{*}{4.0} & $\lambda_{1}=0.35$ & 0.1 & 0.843 & 0.055 & $0.831(1.4)$ & $0.054(1.8)$ & $0.802(4.9)$ & $0.054(1.8)$ \\
\hline & $\lambda_{2}=0.65$ & 0.2 & .844 & .110 & $.834(1.2)$ & $.109(0.9)$ & $.814(3.6)$ & $.107(2.7)$ \\
\hline & & 0.4 & .844 & .219 & $.835(1.1)$ & $.212(0.9)$ & $.818(3.1)$ & $.213(2.7)$ \\
\hline & & 0.8 & .845 & .439 & $.834(1.3)$ & $.434(1.1)$ & $.816(3.4)$ & $.425(3.2)$ \\
\hline & $\lambda_{1}=0.45$ & 0.1 & 0.892 & 0.054 & $0.883(1.0)$ & $0.053(1.9)$ & $0.869(2.6)$ & $0.052(3.7)$ \\
\hline & $\lambda_{2}=0.65$ & 0.2 & .891 & .108 & $.884(0.8)$ & $.106(1.9)$ & $.873(2.0)$ & $.104(3.7)$ \\
\hline & & 0.4 & .892 & .215 & $.885(0.8)$ & $.212(1.4)$ & $.875(1.9)$ & $.208(3.3)$ \\
\hline & & 0.8 & .892 & .430 & $.884(0.9)$ & $.425(1.2)$ & $.873(2.1)$ & $.415(3.5)$ \\
\hline
\end{tabular}

The effect of the solar aureole on the determination of the turbidity coefficient of Yamamoto et al.'s (1968) was also examined. They proposed an algorithm to estimate the turbidity coefficient $\beta$ which correspond to the Angstrom's turbidity coefficient $\beta$ in Eq. (3) when the wavelength exponent $\alpha$ is assumed to be 1.0 , i.e. $\beta=\tau_{M}(\lambda) \cdot \lambda$. According to Coulson (1975), the full aperture angles of the silver-disk, Ångström, Epply and Linke-Feussner pyrheliometers are 5.7, 5.0, 5.7 and $10.2^{\circ}$ in order. We therefore examined the effect of the solar aureole within $\Theta^{*}=3.0^{\circ}$, or the aperture angle of $6.0^{\circ}$. Table 2 shows the percentage errors of $\beta$ due to the aureole flux density for $\gamma=4.0, m=$ $(1.50,0.0)$ and $w=1.5 \mathrm{~g}$. In this table, $I_{0}$ is the solar radiation directly supplied only from the solar disk, $I$ the total flux density including both direct and aureole flux densities, $k$ is the ratio of $I$ to $I_{0}, m_{0}$ is the optical air mass. The quantities $\beta_{0}$ and $\beta$ represent the turbidity coefficients derived from $I_{0}$ and $I$, respectively. The percent- age errors of the Yamamoto et al.'s turbidity coefficient $\beta$ are about $2-3 \%$ and almost independent of the optical air mass and the atmospheric turbidity. As a matter of course, these percentage errors are in good agreement with the mean values of the errors of $\beta_{2}$ and $\beta_{4}$ in Table 1 for the case of $\gamma=4.0$.

\section{Colorimetric properties}

In order to estimate the chromaticity of sky light in the aureole region, monochromatic intensities in the visible spectral region from 0.38 to $0.72 \mu \mathrm{m}$ were calculated for an interval of $0.01 \mu \mathrm{m}$ by interpolating the transfer solution at five wavelengths from 0.35 to $0.725 \mu \mathrm{m}$. The tristimulus values of chromaticity were derived from the table in "The Science of Color" (Optical Society of America, 1973). The wavelengths from 0.73 to $0.77 \mu \mathrm{m}$ were neglected in this calculation, because their tristimulus values are very small and they exist in an absorption band of water vapor. The 
Table 2. Effect of the solar aureole within the scattering angle of $3^{\circ}$ on the determination of the turbidity coefficient defined by Yamamoto et al. (1968) for the case of $\gamma=4.0$ and $w=$ 1.5g. $I_{0}$ is the exact value of the direct solar radiation in $\mathrm{W} / \mathrm{m}^{2}$ and $I$ is the corresponding value including the aureole. $\beta_{0}$ and $\beta$ are the coefficients derived from $I_{0}$ and $I$, respectively, $k$ is the ratio of $I$ to $I_{0}$, and $m_{0}$ is the optical air mass.

\begin{tabular}{c|rcc|ccc|c}
\hline$T_{m}$ & $m_{0}$ & $I_{0}$ & $\beta_{0}$ & $k$ & $I$ & $\beta$ & error(\%) \\
\hline 0.2 & 1.002 & 938 & 0.102 & 1.0038 & 942 & 0.099 & 3.0 \\
& 1.188 & 890 & 0.104 & 1.0044 & 894 & 0.101 & 3.0 \\
& 1.953 & 727 & 0.108 & 1.0071 & 732 & 0.104 & 3.0 \\
\hline \multirow{2}{*}{0.4} & 1.002 & 812 & 0.206 & 1.0054 & 817 & 0.202 & 2.0 \\
& 1.188 & 752 & 0.205 & 1.0088 & 758 & 0.201 & 2.0 \\
& 1.953 & 558 & 0.210 & 1.0138 & 566 & 0.205 & 2.4 \\
\hline \multirow{2}{*}{0.8} & 1.002 & 566 & 0.411 & 1.0148 & 574 & 0.400 & 2.8 \\
& 1.188 & 543 & 0.412 & 1.0174 & 553 & 0.400 & 3.0 \\
& 1.953 & 335 & 0.425 & 1.0268 & 344 & 0.414 & 2.7 \\
\hline
\end{tabular}

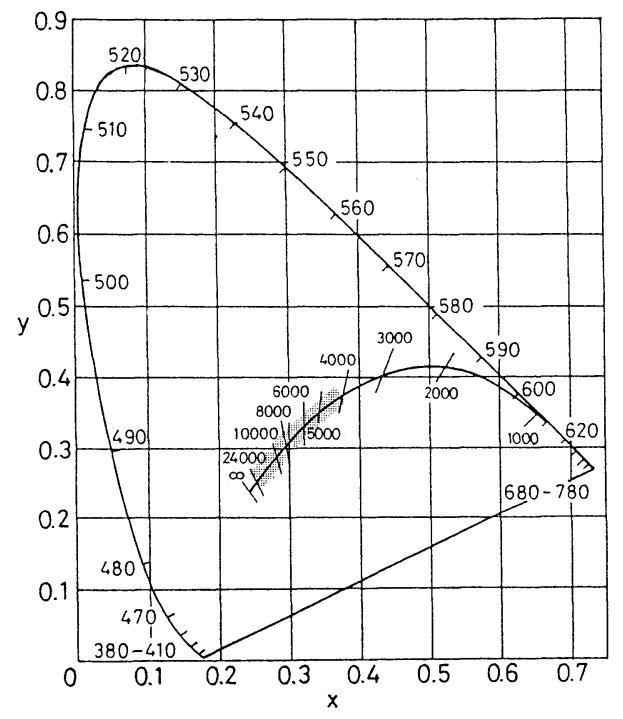

Fig. 7. Chromaticity diagram and the Planckian locus shown on the plane of $(x, y)$. Shaded portion indicates the solar aureole region shown in forthcoming figures.

absorption of ozone was taken into account in the same manner as described in section 3. A general view of the chromaticity diagram is shown in Fig. 7. We will refer to only the shaded region of this figure hereafter. The chromaticity diagrams in the aureole for $m=(1.50,0.0)$ and $\theta_{0}=32.7^{\circ}$ are shown in Figs. 8-10, taking $\gamma$ and
$T_{m}$ as parameters. In these figures, the axes of the chromaticity coordinates $(x, y)$ are inclined to draw the Planckian locus of blackbody radiators as horizontal as possible. The vertical lines show the blackbody temperatures at the intersection on the Planckian locus. Numbers from 1 to 8 indicate the locations of the sky in the solar almucanter, whose azimuth and scattering angles are listed in Table 3. Numbers except 1, 3 and 8 are removed from the cases of $T_{m} \geqq 0.2$ in order only to avoid confusion. The chromaticity of the sun is also shown with a white circle in each part of the figures. Although the sun was treated as a point source in our computations, Box and Deepak (1981) have described that a fairly typical aerosol size distribution leads to an effect of the order of half a percent within a degree of the sun and of several tenths of a percent out to a $5^{\circ}$ scattering angle. Therefore, the effect of the point source of solar radiation can safely be disregarded. On the whole, we can see from Figs. 8-10 that the chromaticities both of the sky and the sun distribute in the immediate vicinities of the Planckian locus. The values of $x$ and $y$ in the pure Rayleigh atmosphere are also listed in Table 3 , though they are out of the range shown in these figures. They represent a blue sky almost independent of scattering angle.

It is noted from Figs. 8-10 that the most reddish region (or the lowest color temperature) 


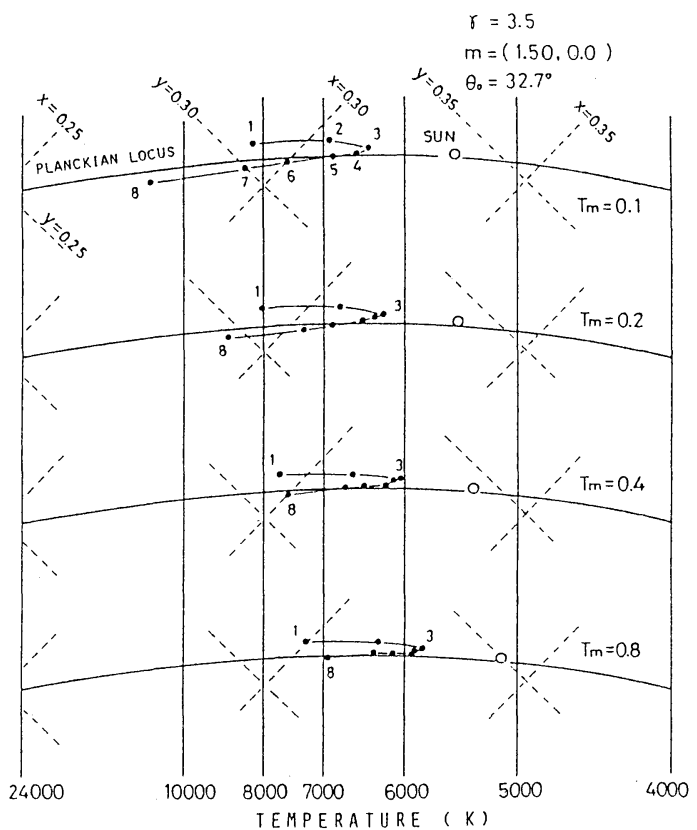

Fig. 8. Chromaticity diagrams in the aureole region for $\gamma=3.5, m=(1.50,0.0)$ and $\theta_{0}=32.7^{\circ}$ and for various values of $T_{m}$. Horizontal solid line is the Planckian locus and the vertical line indicates the black-body temperature on the locus. Numbers from 1 to 8 represent the locations in the sky on the solar almucantar whose scattering angles are shown in Táble 3.

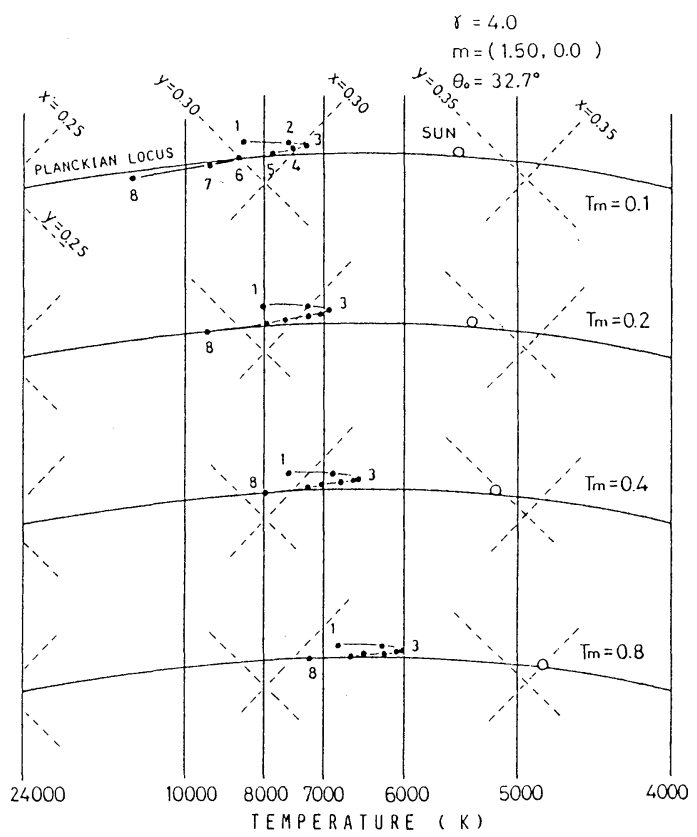

Fig. 9. Same as Fig. 8 but for $\gamma=4.0$.

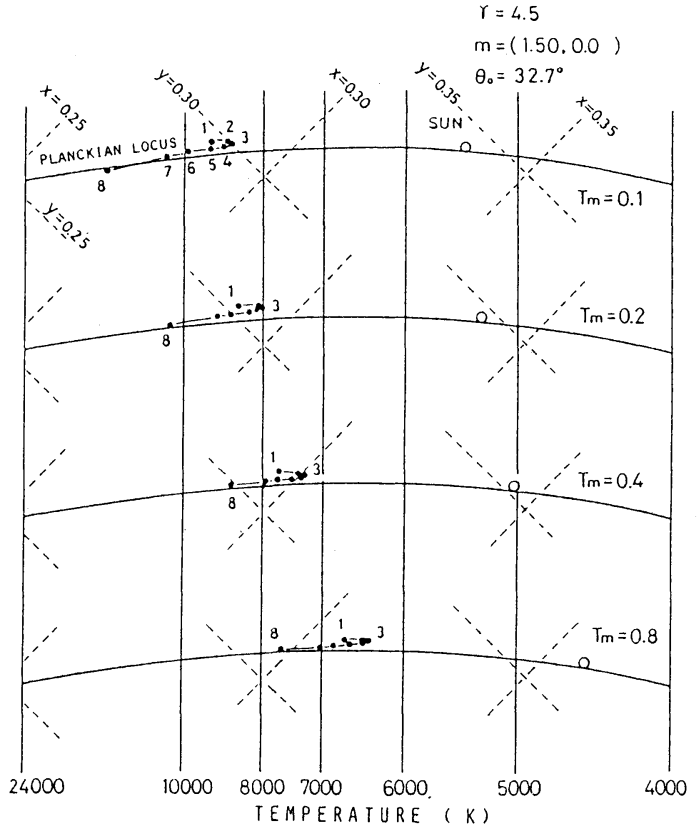

Fig. 10. Same as Fig. 8 but for $\gamma=4.5$.

in the sky exists at the scattering angle of $1.6^{\circ}$ (pt.3) and its location does not change in spite of wide variations in the size distribution and atmospheric turbidity. Hereupon, the adjective "reddish" means the relatively strong contribution of red, although we can see almost whitish even in pt.3. Figure 11 shows the aureole intensities at four wavelengths from 0.40 to 0.70 $\mu \mathrm{m}$. for $\gamma=4.0$ and $T_{m}=0.2$ as a function of the scattering angle $\theta^{*}$. In this figure, the most reddish region around pt.3 just corresponds to the scattering angles from 1 to $4^{\circ}$, where the aureole intensity at $\lambda=0.60 \mu \mathrm{m}$ exceeds the aureole intensity at $\lambda=0.40 \mu \mathrm{m}$. This is the reason why the most reddish region appears around $\theta^{*}=1.6^{\circ}$. Comparisons between the three cases of $\gamma$ in clear conditions of $T_{m} \leqq 0.2$ show that chromaticity values of the direct solar radiation are almost the same for all values of $\gamma$, whereas the diffuse sky radiation is the most bluish for $\gamma=4.5$ and most reddish for $\gamma=3.5$. The change of the chromaticity in both inner $\left(\theta^{*} \leqq 1.6^{\circ}\right)$ and outer $\left(\theta^{*}>1.6^{\circ}\right)$ regions of the aureole is largest for $\gamma=3.5$ and smallest for $\gamma=$ 4.5. In addition, the distance between pts. 3 and 8 decreases with an increase of the atmospheric 
Table 3. Azimuth and scattering angles $\left(\varphi, \theta^{*}\right)$ of the points 1 to 8 shown in Figs. $8-10$ and the corresponding chromaticity coordinates $(x, y)$ of the pure Rayleigh atmosphere for solar zenith angle of $32.7^{\circ}$

\begin{tabular}{c|cc|cc}
\hline Location & $\varphi(\mathrm{deg})$ & $\theta^{*}(\mathrm{deg})$ & $x$ & $y$ \\
\hline SUN & 0 & 0 & 0.3294 & 0.3408 \\
1 & 1.0 & 0.54 & 0.2296 & 0.2183 \\
2 & 2.0 & 1.08 & 0.2296 & 0.2183 \\
3 & 3.0 & 1.62 & 0.2296 & 0.2183 \\
4 & 5.0 & 2.70 & 0.2297 & 0.2184 \\
5 & 10.0 & 5.40 & 0.2296 & 0.2183 \\
6 & 20.0 & 10.77 & 0.2295 & 0.2181 \\
7 & 30.0 & 16.08 & 0.2278 & 0.2161 \\
8 & 60.0 & 31.36 & 0.2288 & 0.2160 \\
\hline
\end{tabular}

turbidity $T_{i n}$ for all values of $\gamma$, together with a progressive displacement of pt.3 to the lower temperature. This feature is also remarkable for $\gamma=3.5$, where pt. 8 moves exceedingly to have a color temperature lower than pt. 1 for $T_{m} \geqq 0.4$. Since the aerosol multiple scattering dominates at large scattering angles especially for $\gamma=3.5$, this feature may be attributed to the multiple scattering due to aerosols. The distance between pts. 1 and 3 does not change for various turbidity conditions, corresponding to the fact that single scattering is dominant in this region of small scattering angles. As for the sun, the chromaticity changes with atmospheric turbidity most noticeably for the case of $\gamma=4.5$, where relative decreases of shorter visible radiations are most conspicuous.

The differences between the chromaticities for $m=(1.50,-0.01)$ and $m=(1.50,0.0)$ are shown in Table 4 for $\gamma=4.0, T_{m}=0.1$ and 0.8 . In clear conditions, the absorbing aerosols make the sky more bluish in all scattering angles, because of a relatively large decrease of diffuse intensities at longer wavelengths, or an increase of relative contribution of the Rayleigh scattering. In turbid conditions of $T_{m} \geqq 0.4$, on the other hand, the sky becomes more reddish with an increase of the scattering angle, because of a rapid decrease of shorter visible radiations with increasing $\theta^{*}$.

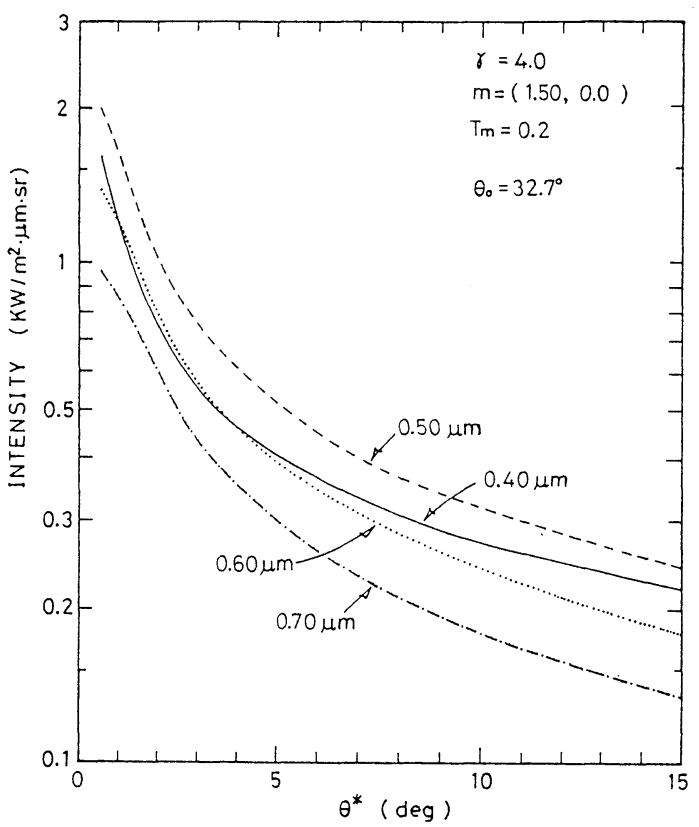

Fig. 11. Aureole intensities versus scattering angle $\theta^{*}$ for $\gamma=4.0, m=(1.50,0.0), T_{m}=0.2, \theta_{0}=32.7^{\circ}$, and $\lambda=0.40,0.50,0.60$ and $0.70 \mu \mathrm{m}$.

Table 4. Differerices in chromaticities between the cases of $m=(1.50,-0.01)$ and $m=$ $(1.50,0.0)$, for ${ }^{\prime}=4.0$ and solar zenith angle of $32.7^{\circ}$

\begin{tabular}{ccccc}
\hline & \multicolumn{2}{c}{$T_{m}=0.1$} & \multicolumn{2}{c}{$T_{m}=0.8$} \\
\cline { 2 - 5 } Location & $\Delta x$ & $\Delta y$ & $\Delta x$ & $\Delta y$ \\
\hline 1 & -0.0004 & -0.0004 & -0.0002 & -0.0002 \\
2 & -0.0003 & -0.0004 & 0 & +0.0001 \\
3 & -0.0002 & -0.0003 & +0.0001 & +0.0003 \\
4 & -0.0003 & -0.0004 & +0.0003 & +0.0004 \\
5 & -0.0005 & -0.0004 & +0.0006 & +0.0007 \\
6 & -0.0008 & -0.0009 & +0.0008 & +0.0010 \\
7 & -0.0010 & -0.0012 & +0.0009 & +0.0011 \\
8 & -0.0015 & -0.0020 & +0.0013 & +0.0016 \\
\hline
\end{tabular}

\section{Concluding remarks}

The flux density of diffuse radiation and the chromaticity were studied in the solar aureole region by the use of a rigorous solution to the equation of radiative transfer. The results are summarized as follows:

(1) The ratio of the aureole flux density to that of the direct-solar radiation is very large at 
shorter visible wavelengths and in turbid conditions especially for the case of $\gamma=3.5$. The ratio of the total aureole flux density integrated from $\lambda=0.30$ to $3.0 \mu \mathrm{m}$ to the total direct-solar radiation increases with an increase of the water vapor content in the atmosphere, due to increasing absorption of the direct-solar radiation in the near infrared region.

(2) The solar aureole affects considerably the values of the Angström's turbidity parameters, $\alpha$ and $\beta$, determined from direct solar radiation measurements. The errors of $\alpha$ and $\beta$ sometimes become several percent or more and cannot be neglected in detailed discussions of radiative properties of the turbid atmosphere. These errors do not dimirish even in very clear conditions. This result suggests that the spectral extinction measurements should be made by a photometer with the aperture angle as narrow as possible especially at shorter visible wavelengths.

(3) The colorimetric property in the aureole region varies considerably place by place and model by model especially for the case of $\gamma=$ 3.5 , where large particles predominate. The most reddish ring is found around the sun at $\theta^{*} \simeq$ $1.6^{\circ}$ and its position does not change for different aerosol size distributions and turbidity conditions. These features are ascribed to the differences in the shape of the forward scattering lobe of the aerosol phase function. The chromaticity for smaller values of $\theta^{*}$ depends mainly on the single scattering due to aerosols, while that for larger values of $\theta^{*}$ is influenced by the multiple scattering. The absorping aerosols make the aureole more bluish in clear conditions, and make the aureole more reddish in turbid conditions.

\section{Acknowledgment}

The authors express their sincere gratitude to Prof. G. E. Shaw at the University of Alaska in Fairbanks, who kindly read a rough draft of this article and provided valuable suggestions.

\section{References}

Ångström, A., 1964: The parameters of atmospheric turbidity. Tellus, 16, 64-75.
1974: Circumsolar radiation as a measure of the turbidity of the atmosphere. Part 2. Appl. Opt., 13, 1477-1480.

Arao, K. and M. Tanaka, 1986: Dependence of the solar aureole upon the optical properties of aerosols and albedo of the ground surface. J. Meteor. Soc. Japan, 64, 743-754.

Box, M.A. and A. Deepak, 1979: Atmospheric scattering corrections to solar radiometry. Appl. Opt., 18, 1941-1949. and 1981: Finite sun effect on the interpretation of solar aureole. Appl. Opt., 20, 2806-2810.

Coulson, K.L., 1975: Solar and Terrestrial Radiation, New York, Academic Press, 322pp.

Deepak, A. and R.R. Adams, 1983: Photography and photographic-photometry of the solar aureole. Appl. Opt., 22, 1646-1654.

Deirmendjian, D., 1957: Theory of the solar aureole, part I: Scattering and radiative transfer. Ann. Geóphys., 13, 286-306.

- 1959: Theory of the solar aureole, part II: Application to atmospheric model. Ann. Geophys., 15, 218-249.

Elterman, L., 1968: UV, visible and IR attenuation for altitudes to $50 \mathrm{~km}$. Environmental Res. Paper, No. 285, AFCRL, Bedford, Mass., 49pp.

International Radiation Commission, 1965: Guide to meteorological instruments and observing practices (published by WMO).

Major, G., 1973: An effect of the circumsolar sky radiation in the Angström pyrheliometric scale. Tellus, 25, 396-399.

McPeters, R.D. and A.E.S. Green, 1976: Photographic aureole measurements and the validity of aerosol single scattering. Appl. Opt., 15, 2457-2463.

Nakajima, T., M. Tanaka and T. Yamauchi, 1983: Retrieval of the optical properties of aerosols from aureole and extinction data. Appl. Opt., 22, 2951-2959.

Optical Society of America, 1973: The Science of Color, 8th ed., Ann Arbor, Mich., Edwards Brothers, $322 \mathrm{pp}$.

Raschke, E. and U. Stucke, 1973: Approximations of band transmission functions by finite sum of exponentials. Beitr. Phys. Atmos., 46, S, 203-212.

Shaw, G.E. and C.S. Deehr, 1975: A photoelectric coronameter for atmospheric turbidity studies. $J$. Appl. Meteor., 14, 1203-1205.

Tanaka, M., T. Nakajima and M. Shiobara, 1986: Calibration of a sunphotometer by simultaneous measurements of direct-solar and circumsolar radiations. Appl. Opt., 25, 1170-1176.

Thekaekara, M.P., 1974: Extraterrestrial solar spectrum, 3000-6000 $\AA$ at $1-\AA$ intervals. Appl. Opt., 13, 518-522.

Vigroux, E., 1953: Contribution a l'etude experimentale 
de l'absorption de l'ozone. Ann. Phys., 8, 709.

Yamamoto, G., M. Tanaka and K. Arao, 1968:

Hemispherical distribution of turbidity coefficient as estimated from direct solar radiation measurements. J. Meteor. Soc. Japan, 46, 287-300.

\section{太陽周辺光の測光学的特性と色度特性}

荒 生 公 雄

(長崎大学教育学部地学教室)

田 中 正之

(東北大学理学部超高層物理学研究施設)

現実的な複数の混濁大気モデルにおける太陽放射伝達の厳密解に基づいて、太陽周辺の天空散乱放射 の測光学的特性おょび色度特性を多様な混濁状態について考察した。太陽近傍の散乱放射は、混濁度の 大きい大気状態において、特に可視の短波長側で著しく増大する。このような一般的な特徵にもかかわ らず、直接日射観測に取り込まれる周辺光の影響による、Ångström の混濁パラメーターのパーセント ・エラーは、混濁した状態よりも清澄な状態で大きくなる。その理由は、清澄状態ではほんの僅かな周 辺光の直達日射への寄与が、エアロゾルの光学的厚さを著しく減少させるためである。太陽周辺光の色 度特性は、大粒子を多く含む大気に招いて空間的に顕著な変化を示すが、最も赤色の強い場所は常に太 陽から約1.6度のところにあって、多様な混濁状態やモデルによる位置の変化は現れなかった。非吸収 性のエアロゾルの場合と比べて、吸収性のエアロゾルによる周辺光の色度分布は、清澄状態では青色が 一層強まり、混濁状態では赤色がより強くなる。 